\title{
Environmental Assessment and Monitoring Framework at the Municipality Scale
}

\author{
Felix Iyalomhe ${ }^{1}$, Philipa Idogho ${ }^{2}$ \\ ${ }^{1}$ Global Change and Sustainability Research Institute, University of the Witwatersrand, Johannesburg, South Africa \\ ${ }^{2}$ Department of Office Technology and Management, Auchi Polytechnic, Auchi, Edo State, Nigeria
}

Email address:

Iyalomhe2003@yahoo.com (Felix I.), philipaidogho@yahoo.com (Philipa I.)

\section{To cite this article:}

Felix Iyalomhe, Philipa Idogho. Environmental Assessment and Monitoring Framework at the Municipality Scale. International Journal of Environmental Protection and Policy. Vol. 3, No. 3, 2015, pp. 57-64. doi: 10.11648/j.ijepp.20150303.11

\begin{abstract}
Negative impacts of developments on the health of humans and the environment in the Waterberg municipality of South Africa are anticipated. An understanding of such impacts demands the integration of relevant environmental monitoring and assessments (i.e. biophysical and socioeconomic) in order to examine the negative impacts before planned developments in the region. Over the years, an integrated approach to environmental monitoring has not been very successful, because of vague conceptualization and lack of clear objectives and priorities linked to the interpretation of roles and responsibilities for compliance with regulatory and management programs (e.g. South African National Environmental Management Air Quality Act No. 39 of 2004 etc.). This paper proposes a conceptual framework as an approach to integrate different environmental monitoring and assessments of biophysical and socioeconomic systems in the context of planned developments. It identifies relevant types of environmental monitoring and assessment and describes how these could be linked, and highlights the concept of an integrated environmental baseline not just as a basis for present and future environmental conditions, but also as a potential link between the various processes and practitioners of all monitoring and assessments; while it attempts to enhance a full understanding of changes in environmental conditions and their likely trends, drivers and impacts. This paper theoretically illustrate the framework using the Waterberg municipality, in order to highlight its potentials as a proactive and integrated approach to understanding changes in environmental conditions and consequent impacts on the health of humans and the environment due to anticipated changes in key environmental parameters. Thus, this paper argues that the framework could provide a systematic procedure to environmental monitoring and assessment, and a coherent understanding of environmental conditions before planned developments at a local scale, by informing concepts and processes that should link various monitoring initiatives and their practitioners.
\end{abstract}

Keywords: Integrated Framework, Environmental Monitoring and Assessment, Human and Environmental Health, Planned Developments, Waterberg Municipality

\section{Introduction}

The Waterberg municipality is described as an economic and development hub in South Africa because of its vast opportunities for industrial, agricultural and forestry developments. The present and planned coal mining fields and coal-fired power stations could have a variety of adverse as well as beneficial effects on ecological and social systems e.g. changes in the natural reserves areas (Waterberg Biosphere Reserve), ambient Air Quality, and demographic trends. Thus, the region represents an environmentally compromised area because of unsustainable trends of developments, partly due to a lack of an integrated understanding of its environmental conditions that are presently described as fragmented, incomplete and often inaccurate.

The Waterberg being a municipality in the Limpopo province possesses high reserves of mineral resources including coal, platinum and lead [27,35]. Rapid development of extensive coal mining is already taking place and is expected to increase in the next decade due to the demand for electricity. Consequently, coal mining in the region has resulted in the production of gaseous and solid air pollutants e.g. sulphur dioxide $\left(\mathrm{SO}_{2}\right)$, nitrogen dioxide $\left(\mathrm{NO}_{2}\right)$, particulate matter $(\mathrm{PM})$ and lead $(\mathrm{Pb})$ that are demonstrated threats to both human and environmental health. Moreover, recent understandings indicate that the area will be vulnerable to changes in ambient Air Quality and its associated impacts on 
humans and the environment due to unsustainable trends of developments. In view of this, the National Department of Environmental Affairs of South African under the Air Quality Act No. 39 of 2004 declared the Waterberg region a National Priority Area for air quality management. The definition of a Priority Area requires that the air quality be monitored as well as the impacts on the health of the environment and humans in order to proactively protect and enhance ambient Air Quality in South African, to prevent severe air pollution and related ecological degradation, and to ensure sustainable development [21,35]. A key aspect of the Act highlights the need for mechanisms and procedures for the establishment of national ambient air quality standards to avoid or control the effects from changes in ambient air quality on human and environmental health. To that end, the Act requires national, provincial and municipal governments to identify priority pollutants and set ambient standards with respect to these pollutants, as well as to integrate air quality planning into their integrated development plans [21].

Several environmental initiatives related to monitoring and assessments of soil, vegetation, birds, insects, and ambient air quality have been conducted in the Waterberg National Priority Areas (NPA). However, this has not led to increased public participation in the protection of air quality and improved monitoring of changes in ambient air quality, much less a complete reduction of the region's vulnerability to effects from developments on the health of humans and the environment. This is due to vague conceptualization and lack of clear objectives and priorities linked to the interpretation of roles and responsibilities for compliance with regulatory and management programs (e.g. the South African Air Quality Act No 39 of 2004). This highlights the need for an explicit integrated environmental monitoring and assessment as a benchmark to determine the trends of air pollution and possible ambient air quality standards, as well as improved knowledge of environmental conditions. Moreover, because of the Air Quality Act, numerous emission-monitoring stations have been established but there is little emphasis to date on the impacts of pollutants on human and environmental health. Thus, there is urgent need for a more integrated approach to environmental monitoring in the region in order to integrate effectively fragmented information and understanding useful for a valid knowledge of environmental conditions and/or baseline before planned developments. That will not only identify relationships and linkages, but it will also support a detailed assessment of potential biophysical and social impacts. Besides, the integration of different environmental monitoring and assessments will be premised on the definition of an interdisciplinary framework aimed at resolving the complex relationship between different knowledge domains on environmental issues. It will also promote a holistic and interactive or collaborative approach to managing interrelated environmental issues through a common objective approach $[4,19,13]$. However, before now, many frameworks aimed at integrated environmental assessment have apparently failed because they have not explicitly considered all relevant monitoring useful to inform environmental decision-making $[23,9,30,29,14]$. This results in incoherent knowledge provided by such assessments that are limited in scope, and thus undermine concerted efforts of practitioners engaged in environmental planning and management.

This paper proposes a framework as well as an approach to integrated environmental monitoring and assessment. It theoretically illustrates such to underscore its potentials for possible integration of biophysical and social impact monitoring and assessments in the context of planned developments. The paper presents four relevant types of environmental monitoring: (1) Environment monitoring to detect and document patterns of possible adverse and beneficial effects; (2) Condition monitoring to determine present conditions and attributes of ecological and human systems; (3) Trends and Drivers monitoring assessment to describe possible causal agents that could bring about changes in the status of human and ecological systems; (4) Impacts monitoring to identify potential changes in the condition of key environmental parameters under specific scenarios of trends and drivers.

This paper illustrates the framework and approach using the Waterberg NPA, and suggests that the relationship between monitoring and assessments is based on the various processes linking all assessments and engaged practitioners. It highlights the integrated environmental baseline as a means to understand the present and future environmental conditions. All assessments feed the integrated environmental baseline that links different but relevant types of weighted evidence from all monitoring and assessments. The framework presented here may help to establish a coherent understanding of environmental conditions in the Waterberg region before planned developments and thus support a proactive assessment of impacts which may occur in the future.

\section{A Framework for Environmental Monitoring and Assessment}

The framework (Fig.1) aims to integrate the implementation of different but related environmental monitoring and assessments by highlighting common concepts and understanding of processes. In particular, it provides a mechanism for practitioners using various environmental approaches to monitoring in order to link them conceptually. The framework theoretically analyzes environmental monitoring in the context of changes in key environmental parameters expected to occur with planned development, and is organized into two broad categories: 'Problem identification' and 'Problem characterization'. It conceptually defines relevant monitoring and their relationships (via processes) within these categories to inform a better understanding of environmental assessment and management and its complexities. The categories comprise four different environmental initiatives that are related to monitoring of trends and drivers, environmental condition and prediction. For example, changes in the biophysical system 
due to changes in rainfall and temperature regimes, and atmospheric composition may result in a broader range of socio-ecological consequences, such as increased deposition of acidic compounds or an increase in airborne particulates. Thus, the framework aims to incorporate relevant data from
Problem
Identification
Problem
characterization

different interdisciplinary research initiatives into an integrated platform that will contribute to enhanced knowledge and a coherent understanding of potential impacts on the health of the environment and humans.

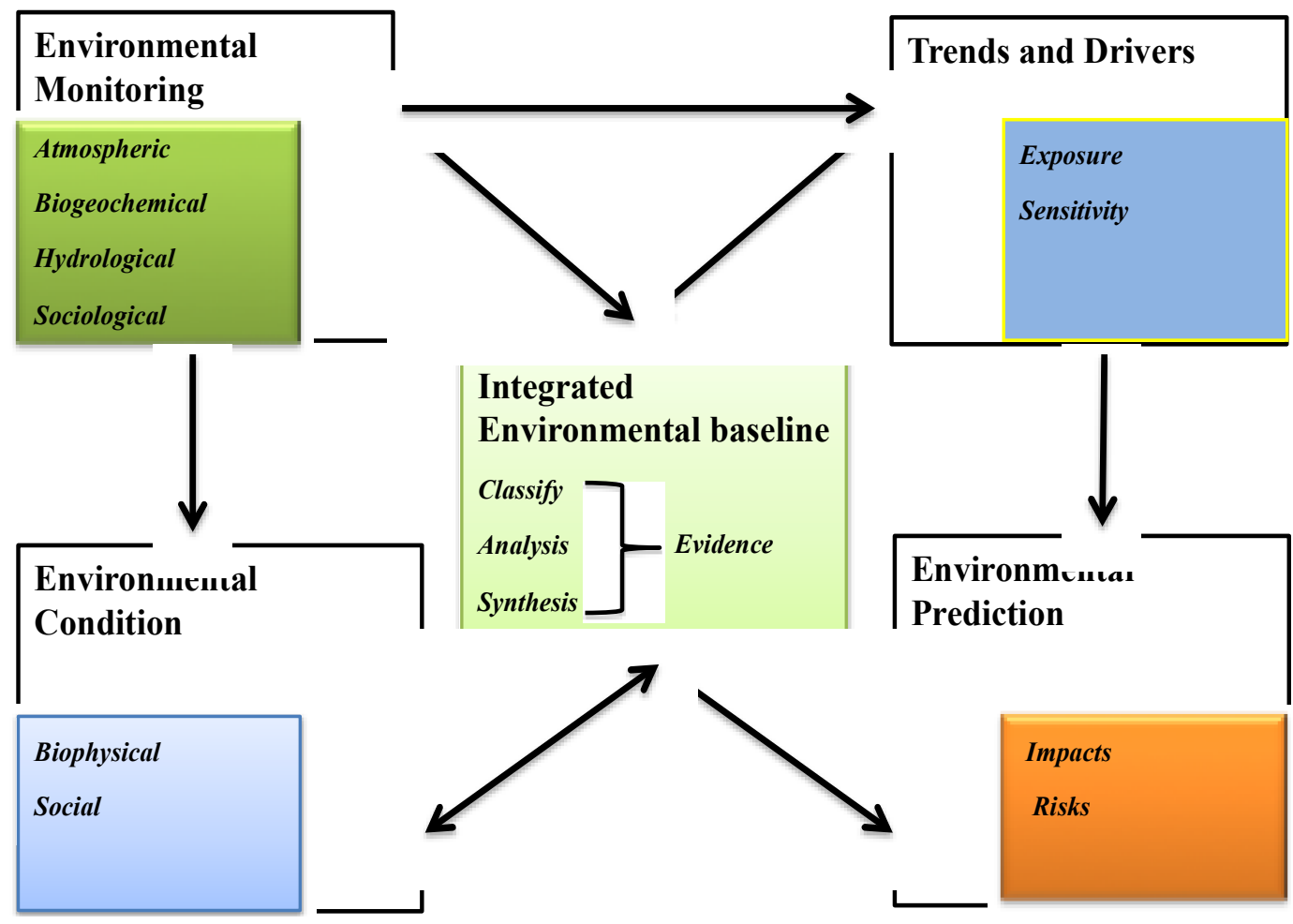

Fig. 1. A conceptual framework for integrated biophysical and socioeconomic monitoring draws on the work of these studies [31,28,21,9]. Environmental monitoring, conditions, trends and drivers, and predictions feed the integrated baseline through varying but related processes of monitoring and assessments.

\section{Framework Approach for Environmental Monitoring and Assessments}

This consists of categories that attempt to underscore relevant monitoring and assessments needed for potential regional environmental problems. The categories are therefore helpful in understanding how key environmental parameters have responded to historical pressures related to current developments and how these might likely respond to planned developments. Hence the framework, through these categories, establishes the changes in key environmental parameters and uses this as a basis to determine possible changes in environmental conditions and consequent effects on socio-ecological systems. Accordingly, it identifies potential target areas for monitoring of a wide range of key environmental parameters, and considers relevant outcomes in order to analyze a wide range of activities and their likely effects on natural and human systems through changes in the biophysical and social aspects of the environment. In 
weighted joint-body of evidence, but also highlights the inherent relationships between the various processes of each monitoring and their links to the joint-body of evidence, which is useful for the integrated baseline. It underscores the significance of processes of classifying, analyzing and synthesizing different bodies of evidence in each monitoring.

First, the classifying stage combines several joint-bodies of evidence from different monitoring according to criteria-guided judgment and the quality of the process used to derive the body of evidence, which is inherently flexible and transparent. Thus, it categorizes the body of evidence into significant groups that share common qualities and attributes [31]. Next, the analyzing stage evaluates the categorized, weighted body of evidence from all monitoring assessments based on specific logic and assumptions, to define different weighted joint-bodies of evidence and the relevance of each to the integrated baseline without the unnecessary repetition of evidence. Lastly, the synthesizing stage aggregates differently weighted joint-bodies of evidence in the context of associated uncertainties to define the integrated baseline in which weights express the overall quality and relevance of each body of evidence to the baseline outputs.

\subsection{Environmental Monitoring}

Environmental monitoring refers to the long-term, standardized measurement and observation of relevant physical, chemical, and/or biological variables designed to detect and document patterns of possible environmental change $[15,2,8,37]$. It involves criteria with which to identify monitoring sites and to generate a historical database, and uses this to address a particular problem (single-objective monitoring) or several problems (multi-objective monitoring). However, environmental monitoring is often limited by time and resource constraints, and in particular, a lack of clear and precise objectives that are also related to limited resources and time [1]. Despite this, it has proved to be indispensable to environmental impact assessments.

Within the framework in Fig. 1, environmental monitoring and assessments have multi-objectives because they include the observations of chemical, bio-accumulative, biological, health and ecosystem conditions etc., [33] as parallel but related activities aimed at the identification of changes within different key parameters of the environment. For example, in socioeconomic assessments, environmental monitoring can be aimed at exploring diverse social changes (e.g. perceptions and attitudes) and how these vary over time with respect to changes in the natural environment due to developments, and the expected goals and needs of people. With this, environmental monitoring provides the essential and relevant inputs to other assessments, to efficiently evaluate cumulative effects due to changes in key environmental parameters. Accordingly, environmental monitoring can feed condition, trends and drivers' assessments. However, if a particular monitoring aims to understand how and why changes in the environmental condition will occur, we need to interpret historical trends of changes (i.e. biophysical and social) in order to identify the relationship between drivers and possible adverse or beneficial effects. Environmental assessments, which aim to identify the direct and indirect effects of mining activities on socio-ecological systems, would investigate the biophysical and social changes by measuring functions of the environment and its ecosystems and attributes of human population, coupled with the relevant design and analysis of effects [15]. Thus, monitoring supports the definition of a valid baseline output that ultimately reflects the environmental condition before the occurrence of anticipated changes in key environmental parameters. For this purpose, environmental monitoring must include a wide range of insights, including the interactions and linkages of multiple monitoring and assessments within the natural and built environment, because individual variables of one system are influenced by and affect other variables in other systems $[17,15]$.

\subsection{Environmental Condition Monitoring}

This examines the monitored key environmental parameters to determine the present condition and attributes of ecological and human systems. It detects variations in the condition and attributes over time, and thus provides invaluable information about trends in ecosystem function and ecological elements (structure, components and processes) with respect to spatial and temporal scales [2,22]. Accordingly, the environmental condition seems to play a crucial role in environmental impact and quality assessment, and it relies heavily on environmental monitoring. To that end, there may be comparative analyses conducted of what has happened, what is happening and what is expected, given a specific environment and its unique, potentially affected key parameters [9]. In particular, condition assessments for anticipated effects due to developments will help to establish the condition of selected key environmental parameters and to identify sensitive areas and associated threats. It will document information in a manner that allows different practitioners to assess the entire environmental conditions (biophysical and social) within a region.

Environmental conditions for changes to socio-ecological systems will involve the comparative analysis of attributes of populations, communities or ecosystems with those that would be expected based on planned developments. For both human and ecological health, monitoring data are analyzed to determine whether the frequency and severity of effects from development might be higher than presumed, given the changes in population and its attributes [9]. However, this might be undermined by a lack of adequate knowledge of the basic ecological elements and the difficulty in defining the desired standard for the environmental condition. In a typical monitoring site, for example, where human health is partly determined by effective regulatory measures, an environmental condition may be applied to examine whether these measures are observed or not. In contrast, the environmental condition for environmental health is based on the knowledge of normal ranges of variation, which are not fully understood because of the complexities inherent to key environmental parameters. 
A particular environmental condition analysis can initiate predictive assessments that result in the determination of how variations in trends and drivers would alter the present condition of the environment. For example, if the present environmental condition highlights changes in ambient Air Quality due to developments in the area (extensive coal mining), trends and drivers' assessments may be necessary to characterize the various drivers e.g. priority pollutants and their likely trends over time. Environmental condition provides relevant insights into the present state of key environmental parameters, which support the assessment of potential effects as well as describing the present environmental conditions.

\subsection{Trends and Drivers Monitoring}

Trends and drivers describe possible causal agents that could bring about changes in key environmental parameters. In particular, this identifies possible patterns of changes, their range of causal agents and likely specific effects on the condition of the environment and humans [23, 32]. Trend and driver assessments identify and characterize multiple and often interacting drivers, which work over spatial and temporal scales in an intermittent manner, to apportion exposure to changes in trends of environmental effects. The drivers of change in ambient air quality may be found by examining several emission inventories, historical monitoring data of priority pollutants, deposition agents, etc. It is not always necessary to perform both trends and drivers' assessments because in some cases the identification of trends also serves to identify the relevant driver. However, both the trends and the drivers of change in key environmental parameters usually must be adequately determined before there can be absolute prediction of environmental effects. A possible approach to analyzing the trends and drivers of changes in the status of ecological and human systems in relation to developments calls for an inclusive analysis of a range of present developments in order to identify changes of trends within the areas. Moreover, trends and drivers should be based on an integrated approach that allows elucidation of how regional trends may be linked to specific drivers in an area. This helps to identify relevant uncertainties as well as scenarios of exposure and sensitivity needed for the characterization of potential effects on the natural and social environments. On the other hand, trend and driver assessments may depend on existing national and regional standards for environmental conditions, which might be unreliable in areas where there are no strong considerations for such standards.

\subsection{Impacts Monitoring}

Environmental prediction estimates potential changes in key environmental parameters under specific trend and driver scenarios. It is either aimed at the evaluation of consequences or the measurement of magnitude of consequences under scenarios of exposure and sensitivity in the context of uncertainties [24]. In some contexts, prediction evaluates historically monitored data to characterize current environmental conditions or analyses associated with causal agents to predict a range of potential effects on distinct ecological and social systems. It could provide useful insights into possible changes in the environmental baseline based on comparative analyses of environmental conditions and possible trends and drivers.

According to Fig. 1, prediction monitoring and assessments may be fed by environmental condition, trends and drivers' assessments. However, these are equally important, even though they provide different insights at different stages. For the former, the insight may serve as a basis for the evaluation of changes in the characteristics of ecological and social systems under future changes in key environmental parameters. In this case, prediction will be able to describe potential impacts on diverse socio-ecological systems. For the latter, insights may be related to exposure and sensitivity; useful for identifying those areas within the region where specific socio-ecological systems would be most impacted by changes in key environmental parameters.

Environmental prediction may particularly examine how changes in the state of ecological systems and consequent changes and impacts in social systems could be identified and characterized. However, in some cases where there are no studies of a specific ecological state, prediction could serve as a means of inferring environmental conditions, as well as providing a baseline output. In this case, the results of prediction could be sufficient to inform decision-making that is related to managing huge and obvious risks due to increased developments.

\section{Applying the Framework Approach}

This paper attempts to illustrate how the framework approach might relate to the management of the health of humans and the environment within the context of the South African Air Quality Act, by theoretically illustrating the various steps of the framework and how such could include information from different biophysical and social activities that are already conducted and/or being conducted within the Waterberg municipality. That includes areas that are potentially impacted by current and planned developments as well as areas that are less impacted but are located around an environmental gradient, for example, the Marapong and Onverwacht human settlements, because of their close proximity to the Eskom's Matimba and Medupi coal-fired power stations and the Grootegeluk coal field mine.

This aims to monitor and assess changes in key environmental parameters related to the quality and conditions of streams, ambient air, vegetation, soil and humans. It will also include possible trends and drivers, which can be ascribed to plan developments in order to integrate a wide range of observed data and modeled outputs that will be analyzed to describe the health of the environment and humans in the municipality.

\subsection{Environmental Monitoring}

The monitoring of key environmental parameters related to 
biophysical and social systems in the Waterberg region may involve relevant procedures and criteria that are crucial to observe and measure the quality/status of the health of humans and the environment, especially in the hotspots (i.e. NPA) where current development activities related to coal mining and coal-fired power stations is already posing adverse as well as beneficial effects on the environment. For example, this will employ a multi-objectives monitoring approach to the condition of ambient air, streams, and the diversity of vegetation and birds, as well as social changes in the hotspots, based on long-term observations of pollutants loading (airborne particulates, sulphur dioxide and oxides of nitrogen, carbon monoxides etc.) and the examination of emissions inventories in order to identify changes in key environmental parameters and possible existing trends in biophysical and social changes. Ultimately, monitoring may help to identify priority pollutants and associated human and natural drivers as well as providing insights into the trends of these pollutants in the hotspots. Moreover, it would reveal how planned developments might affect key environmental parameters and how this could support a viable assessment of biophysical and social changes and impacts as well as promote sustainable development.

\subsection{Environmental Condition Monitoring}

This will reflect changes in the condition and attributes of biophysical and social systems in the hotspots according to changes in the monitored key environmental parameters. That is, it will empirically examine, for example, changes in the quality of ambient air and streams, and the perception of people about the condition of the environment, based on the monitored and observed information of pollutant loading and emission inventory in the transect sites. This will ascertain how changes in key environmental parameters due to coal-fired power stations and coal mining fields have reflected on the health of the environment and humans in the Waterberg NPA. Moreover, this will help to identify whether the frequency and severity of biophysical and social changes might be higher than assumed, considering planned developments. Condition monitoring usefully provide relevant indicators required to inform effective monitoring networks that are needed for valid knowledge of environmental conditions and the successful assessment of potential biophysical and social changes and impacts in the context of changes in key environmental parameters.

\subsection{Trends and Drivers' Monitoring}

This will identify and examine natural drivers (e.g. relevant ecological features, topography, climate systems) and social drivers (e.g. development projects, infrastructures, demography) within and in close proximity to transect sites in the Waterberg NPA in order to highlight, on the one hand, specific socio-ecological systems that will be more prone to changes in environmental conditions, and on the other hand, significant drivers and trends of those changes, and how these are related to changes in the health of humans and the environment. It will also identify which driver is responsible for significant trends, knowing that different trends could have similar drivers but different impacts and risks. For example, activities of coal mining fields and coal-fired power stations pose different pollutants (gaseous and solid) that interact in the atmosphere and culminate in specific impacts on the environment and humans e.g. changes in diversity and distribution of vegetation and species of birds, as well as the human respiratory system. Trends and drivers' monitoring and assessments will highlight specific areas of the Waterberg NPA where there may be multiple and interacting priority pollutants, and thus high exposure and sensitivity to changes in key environmental parameters and their consequences on daily and seasonal scales. This relates much more to hotspots where stringent and urgent measures will be needed to manage the negative effects from current and planned developments.

\subsection{Impacts Monitoring}

This may employ a predictive modeling approach to analyze the impacts/risks from changes in environmental conditions with respect to the identified trends and drivers, and how this will reflect on the health of humans and the environment. For example, this will measure which trend in solid and gaseous pollutants and resultant pollutant loading on soil and streams would pose the worst impacts and risks e.g. acid rain resulting from $\mathrm{SO}_{2}$ on vegetation, soil, animals (especially in aquatic ecosystems, that is fish, insects etc.), monuments, and drinking water in the hotspots. Impacts monitoring and assessments may inform the understanding of potential impacts on the health of humans and the environment, even if there is no valid knowledge of environmental conditions before the planned industrial developments. It helps to assess and understand how impacts and risks due to changes in pollutants' loading will vary over time, and thus what level of developments will be ideal for acceptable ambient Air Quality standards in South Africa e.g. $26000 \mathrm{ppbv}$ for carbon monoxide, 106ppbv for nitrogen oxide, $1340000 \mathrm{ppbv}$ for sulphur dioxide [35] etc., as well as sustainable environmental decision-making in the hotspots.

\subsection{Integrated Environmental Baseline}

This will attempt analyze and integrate different weighted evidence produced by all monitoring and assessments, to establish a coherent understanding of environmental conditions (i.e. due to biophysical and social changes) with respect to key environmental parameters in the Waterberg NPA. This serves as a basis for the assessments of potential impacts/risks under present scenarios of trends and drivers of changes in parameters. Moreover, the baseline assessment will analyze uncertainties in the processes of all monitoring and assessments based on a systematic approach to weighing of weighted evidence in order to make sure uncertainties within criteria, value judgments and choices made by practitioners are addressed. The protection of human and environmental health will be dependent on such assessment outcome and its application. Thus, baseline assessment would provide 
significant indicators for effective management of vital biophysical and social systems by informing the understanding of an integrated environmental condition before planned developments.

\section{Conclusion}

In this paper, a framework approach was proposed to provide significant insights into the conceptual understanding of integrated environmental monitoring and assessments, in order to push for a more coherent and sustainable environmental planning and management. This is because the framework draws on a broad range of multidisciplinary expertise and approaches and their linking processes, and thus creates a mechanism for this knowledge to be shared and related in ways that allow understanding of common concepts and approaches within different environmental monitoring and assessments. This, the paper suggested, will not only make environmental monitoring and assessments achieve its full potential as a sustainable mechanism, but it will also make it more applicable and realistic.

The framework approach presents a conceptual procedure for the assessment of pertinent biophysical and socio-economic impacts due to developments, based on outputs from multi-objectives monitoring that engages practitioners of different environmental programs, and thus helps focus different expertise towards a common objective (i.e. integrated environmental baseline). The framework supports the monitoring and assessment of impacts systematically by identifying relevant trends and drivers of changes in key environmental parameters as well as likely changes in environmental conditions, which are necessary to decide whether, and how, to proceed with planned developments in particular circumstances. For example, in the Waterberg NPA, where coal mining activities and coal-fired power stations have resulted in ambient air quality being monitored as well as their impact on the environment and human health, the framework would support the assessment of impacts on the environment and humans by identifying distinct but related monitoring that can be assessed separately and then brought together again in a manner that tries not to undermine the desired integration. This would provide explicit and detailed provisions for management and a viable resource for relevant regulatory programs that are designed to abate, for example, negative impacts on the environment and humans in the Waterberg NPA.

Moreover, the framework approach seeks to inform conceptually the understanding of processes that link distinct but related environmental monitoring and assessments, including their participants, and how they could meet and interact, thereby moving the ladder of integrated environmental assessment towards the practice end rather than the principle end that is often the basis for previous multi-disciplinary assessments. Accordingly, the framework approach supports collaborative environmental monitoring and explicit assessment, even though nowadays environmental assessments are often designed for different objectives in different periods according to different approaches. In order to allow regional government as well as relevant stakeholders to have a clear understanding of changes in environmental conditions under planned developments, and thus help them to avoid some of the costly mistakes that have been made during industrial development in Europe and North America.

Finally, it should be emphasised that it is not a framework to structure biophysical and socio-economic changes that may proceed or result in impacts, but rather it is a way of identifying pertinent causal factors (i.e. trends and drivers) of impacts, in order to understanding possible changes in environmental conditions.

\section{Acknowledgements}

This study was supported by grant-B8749.R01 from the Carnegie Corporation of New York to the Global Change and Sustainability Research Institute at the University of the Witwatersrand.

\section{References}

[1] Abaza H, Bisset R, Sadler B. Environmental impact assessment and strategic environmental assessment: towards an integrated approach. UNEP/Earthprint; 2004.

[2] Beanlands GE, Duinker PN. An ecological framework for environmental impact assessment in Canada. 1983. Available from:

http://epe.lac-bac.gc.ca/100/200/301/ceaa-acee/ecological_fra mework-e/23E.PDF

[3] Burton GA, Batley GE, Chapman PM, Forbes VE, Smith EP, Reynoldson $\mathrm{T}$, et al. A weight-of evidence framework for assessing sediment (or other) contamination: improving certainty in the decision-making process. Hum Ecol Risk Assess 2002;8:1675-96.

[4] Born SM, Sonzogni WC. Integrated environmental management: strengthening the conceptualization. Environmental Management. 1995;19(2):167-81.

[5] Bryman A. Integrating quantitative and qualitative research: how is it done? Qualitative research. 2006;6(1):97-113.

[6] Canter LW. Environmental impact assessment. McGraw-Hill: New York; 1977.

[7] Chan NY, Ebi KL, Smith F, Wilson TF, Smith AE. An integrated assessment framework for climate change and infectious diseases. Environmental Health Perspectives. 1999; 107(5):329.

[8] Chapman DV. Water quality assessments: a guide to the use of biota, sediments and water in environmental monitoring. E \& Fn Spon: London; 1996.

[9] Cormier SM, Suter II GW. A framework for fully integrating environmental assessment. Environmental Management. 2008;42(4):543-56.

[10] Dubé M, Munkittrick K. Integration of effects-based and stressor-based approaches into a holistic framework for cumulative effects assessment in aquatic ecosystems. Human and Ecological Risk Assessment. 2001;7(2):247-58. 
[11] Edwards CA. Assessing the effects of environmental pollutants on soil organisms, communities, processes and ecosystems. European Journal of Soil Biology. 2002;38(3):225-231.

[12] Eggenberger M, Partidário MR. Development of a framework to assist the integration of environmental, social and economic issues in spatial planning. Impact assessment and project appraisal. 2000;18(3):201-7.

[13] Gough C, Castells N, Funtowicz S. Integrated Assessment: an emerging methodology for complex issues. Environmental Modeling \& Assessment. 1998;3(1-2):19-29.

[14] Hisschemöller M, Tol RS, Vellinga P. The relevance of participatory approaches in integrated environmental assessment. Integrated Assessment. 2001;2(2):57-72.

[15] Humphrey CL, Faith DP, Dostine PL. Baseline requirements for assessment of mining impact using biological monitoring. Australian Journal of Ecology. 1995;20(1):150-66.

[16] Jabareen, Y. A new conceptual framework for sustainable development. Environment Development and Sustainability. 2008;10(2),197-192.

[17] Karr JR. Biological monitoring and environmental assessment: a conceptual framework. Environmental Management. 1987;11(2):249-56.

[18] Margerum RD. Integrated environmental management: moving from theory to practice. Journal of environmental planning and management. 1995;38(3):371-92.

[19] Margerum RD. Integrated environmental management: lessons from the Trinity Inlet Management Program. Land use Policy. 1999;16(3):179-70.

[20] Munns WR, Kroes R, Veith G, Suter II GW, Damstra T, Waters MD. Approaches for integrated risk assessment. Human and Ecological Risk Assessment. 2003;9(1):267-72.

[21] National Environmental Management: Air Quality Act, No. 39 of 2004. Accessed on 3 March 2014, available at http://www.environment.gov.za. Republic of South Africa (2004).

[22] Quinlan T, Scogings P. Why biophysical and social scientists can speak the same language when addressing sustainable development. Environmental Science \& Policy. 2004;7(6):537-46.

[23] Rounsevell MDA, Dawson TP, Harrison PA. A conceptual framework to assess the effects of environmental change on ecosystem services. Biodiversity and Conservation. 2010;19(10):2823-42.

[24] Rothman DS, Robinson JB. Growing pains: a conceptual framework for considering integrated assessments. Environmental Monitoring and Assessment. 1997; 46(1-2): 23-43.

[25] Smith ML. Environmental impact assessments: the roles of predicting and monitoring the extent of impacts. Marine and Freshwater Research. 1991;42(5):603-14.

[26] Slootweg R, Vanclay F, van Schooten M. Function evaluation as a framework for the integration of social and environmental impact assessment. Impact Assessment and Project Appraisal. 2001;19(1):19-28.

[27] StatsSA (Statistics South Africa). Municipality Fact Sheet. Published by Statistics South Africa. Census, 2011.

[28] Stem C, Margoluis R, Salafsky N, Brown M. Monitoring and evaluation in conservation: a review of trends and approaches. Conservation Biology. 2005;19(2):295-309.

[29] Suter II GW, Vermeire T, Munns Jr WR, Sekizawa J. An integrated framework for health and ecological risk assessment. Toxicology and Applied Pharmacology. 2005;207(2):611-6.

[30] Suter II GW. Ecological risk assessment. CRC press; 2006.

[31] Suter II GW, Vermeire T, Munns WR, Sekizawa J. Framework for the integration of health and ecological risk assessment. Human and Ecological Risk Assessment. 2003;9(1):281-301.

[32] Suter II GW, Cormier SM. Why and how to combine evidence in environmental assessments: Weighing evidence and building cases. Science of the Total Environment. 2011;409(8):140617 .

[33] Toth FL, Hizsnyik E. Integrated environmental assessment methods: Evolution and applications. Environmental Modeling \& Assessment. 1998;3(3):193-207.

[34] Van der Oost R, Beyer J, Vermeulen NP. Fish bioaccumulation and biomarkers in environmental risk assessment: a review. Environmental Toxicology and Pharmacology. 2003; 13(2): $57-149$.

[35] Venter AD, Vakkari V, Beukes JP, Van Zyl PG, Laakso H, Mabaso D, Tiitta P, Josipovic M, Kulmala M, Pienaar JJ, Laakso L. An air quality assessment in the industrialized western Bushveld Igneous Complex, South Africa. South African Journal of Science. 2012;108(9-10):1-10.

[36] WHO. Report on Integrated Risk Assessment. World Health Organization, Geneva, Switzerland. WHO/IPCS/ IRA/01/12; 2001.

[37] Lovett GM, Burns DA, Driscoll CT, Jenkins JC, Mitchell MJ, Rustad L, et al. Who needs environmental monitoring? Frontiers in Ecology and the Environment. 2007;5(5):253-60. 